\section{Heredity of Two Types of Normal Colour Vision}

THE anomaloscope is used to diagnose red and green colour blindness and its four or six sub-types. In the apparatus the lower half of a circular plane is illuminated by a yellow light of wavelength $589 \mathrm{~m} \mu$, and in the upper half red $(670 \mathrm{~m} \mu)$ and green light $(546 \mathrm{~m} \mu)$ are mixed. It is possible, by changing the proportion of red and green illumination, to make the two halves look the same; the proportion of red and green lights required is called the Rayleigh equation, which is accepted by individuals with normal colour vision, but colour blind people react in different ways. On the anomaloscope which I used (model II, Schmidt and Haensch, Berlin) it is possible to change the wavelength of the monochromatic yellow light to make it more and more yellow green, or more and more orange, while the red and green lights are shifted in a similar manner. Rayleigh equations can be found for these wavelengths. I have built up a system of nine equations with the yellow light varying from $574 \mathrm{~m} \mu$ to $603 \mathrm{~m} \mu$.

When these nine equations are recorded for males it appears that some of them show a series of smaller values, while others show a series of larger values. There might be some overlapping in places, but on the whole the males can be divided into two groups, with two normal properties, which I have called protopia and deuteropia, denoted by $\mathrm{P}$ and $\mathrm{D}$ (both for the property and for the gene which is supposed to be responsible for the property). With the same anomaloscope it can be shown that the protopic individuals have their greenpoint (when they see green and not yellow or blue) at about $515 \mathrm{m \mu}$; the others have their greenpoint at $525 \mathrm{~m} \mu$.

Females can be divided into the same two groups, but about fifty out of a hundred of them show a third type of reaction. They behave as deuteropics in the orange region (the $D$ dominates, but not completely), and as protopies in the green tinted region (the $P$ dominates, but not completely).

I propose that these properties derive from hereditary factors in the $X$ chromosome, from two mutant allelomorphs in one cistron. This would mean two genotypes in the male, $P$ and $D$, with frequencies-which are also the gene frequencies in the population-of 60 per cent and 32 per cent to 8 per cent, which is the frequency of colour blindness in males, and there would be the two phenotypes, protopia and deuteropia. In females there would be three genotypes, $P P, P D$ and $D D$, and three phenotypes, protopia, intermediary (supposed to be the heterozygotes $P(D)$ and deuteropia. The heterozygous group has a greenpoint at about $520 \mathrm{m \mu}$, with some overlapping with the other groups of greenpoints.

Because of the intermediate nature of the reactions of the supposed heterozygous group, diagnosis might not be so easy for females as for males. It is made more difficult -it is almost impossible to be accurate-in the group, expected to be about 15 per cent of all females, who are heterozygous for the genes for colour blindness. These females (eight (12) groups with $P$ or $D$ in the one $X$ chromosome and one of the four (6) genes for colour blindness in the other $X$ chromosome) show atypical reactions with respect to the nine equations, atypical reactions which suggest colour blindness.

Results of family examinations are given in Tables 1 and 2.

These two tables show agreement with the hypothesis discussed previously for the mode of inheritance. There was one exception: a $\mathrm{P}$ "father" and D "daughter". I cannot be sure that the determinations are correct, but the most likely explanation is that the $\mathrm{P}$ male is not the true father to this eldest daughter, although he could be the father to the younger daughter, who was PD. Even with this exception the two tables are convineing evidence of the validity of my hypothesis.
Table 1. THE P AND D DIAGNOSES FOR MOTHERS AND THETR SONS

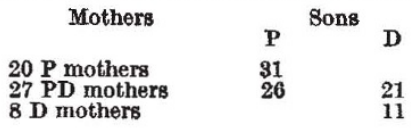

Table 2. THE P, PD AND D DIAGNOSES FOR GROUPS OF PARENTS AND THEIR DAUGHTERS

Parents
$21 \mathrm{P} \times \mathrm{PP}$
$15 \mathrm{P} \times \mathrm{PD}$
$1 \mathrm{P} \times \mathrm{DD}$
$8 \mathrm{D} \times \mathrm{PP}$
$8 \mathrm{D} \times \mathrm{PD}$
$6 \mathrm{D} \times \mathrm{DD}$
Daughters 38 15
15
4.

Based on these facts, I suggest that these hereditary factors have one locus in one cistron in the $X$ chromosome, with two mutants for normal colour vision and four (6) for defective colour vision.

Georg H. M. WaAler

Institute of Forensic Medicine,

Rikshospitalet,

Oslo 1.

Received May 3, 1967.

\section{No Simple Pattern of Inheritance in Ability to smell Solutions of Cyanide}

IN 1950, at the Cold Spring Harbor Symposium on the origin and evolution of man, Mourant commented: "It is most important that more new markers be sought and found for the human chromosomes." As an example of a possible new marker he remarked that: "One person out of four fails to smell hydrogen cyanide, a proportion suggesting a balanced polymorphism"1.

Since then the ability to detect the odour of hydrogen cyanide has been studied in populations in Europe ${ }^{2}$, Africa ${ }^{3}$, India $^{4}, \operatorname{Japan}^{5}$ and Australia ${ }^{6}$ with some evidence of differences in the frequency of "non-smellers". Kirk and Stenhouse ${ }^{6}$ and Fukumoto et al..$^{5}$ investigated families, and suggested that the trait "inability to smell hydrogen cyanide" was inherited as a sex linked recessive, but their families showed some exceptions to the expected results of that hypothesis?. Huser et al. ${ }^{2}$, by similar studies, showed that this trait is neither recessive nor sex linked, and they concluded that it is inherited as a dominant, probably autosomal.

Published reports on the detection of hydrogen cyanide odour are based on a variety of methods of detection and arrangements for presenting the gas to the subject. These variations have made exact comparison between the various reports impossible.

In an attempt to evaluate further the trait for detection of this odour, we have carried out a series of studies using a serial dilution technique similar to that of Harris and Kalmus ${ }^{8}$ for phenylthiocarbamide taste testing except the solutions are smelled rather than tasted. A solution of $10 \mathrm{~g}$ of potassium cyanide in $100 \mathrm{ml}$. of distilled water was diluted by a factor of four in eleven serial steps. Of the resulting twelve solutions the strongest was a million times more concentrated than the weakest. This range of concentrations has been found to cover the sensitivities of most adult humans in our test system.

In the test procedure, the subject was presented with a rack of twelve $1 \mathrm{in}$. diameter, stoppered, test-tubes. Eleven contained $50 \mathrm{ml}$. of a serial dilution, and one identical tube contained distilled water. The subject was instructed to smell the water and then each of the cleven tubes in succession and report if the tube smelled like the water or smelled different. The tubes were presented to the subject in order from the most dilute to the most concentrated. The first tube which provoked a response difference from water was considered to be the threshold and its rank is used as the score in tabulation and calculation. 